\title{
Redesain Permukiman Kumuh dengan Pendekatan Incremental
}

\author{
Muhammad Jehan Aldilla dan Asri Dinapradipta \\ Departemen Arsitektur, Fakultas Teknik Sipil dan Perencanaan, Institut Teknologi Sepuluh Nopember (ITS) \\ e-mail: asdina_p@its.ac.id
}

\begin{abstract}
Abstrak-Mayoritas penduduk permukiman kumuh yang tidak sehat dapat mempengaruhi kualitas masyarakat kota. Kualitas masyarakat kota yang buruk dapat menghambat pertumbuhan kota itu sendiri. Upaya dalam meningkatkan kualitas masyarakat nya dapat dilakukan dari peningkatan kualitas hunian nya. Setelah adanya peningkatan dari kualitas, sebuah hunian selayak nya dapat berkembang untuk masa depan, karena kebutuhan dari manusia yang juga ikut berkembang seiring perkembangan zaman. Peranan arsitektur pada dasarnya adalah memfasilitasi dan mengakomodasi kebutuhan dan aktivitas manusia. Melalui peranan arsitektur tersebut, obyek rancang kawasan ini berfungsi untuk memenuhi kebutuhan dari penghuni nya dan layak digunakan sesuai standar dari Green Architecture dan dapat berkembang sesuai kebutuhan dengan metode Incremental, yang secara harafiah berarti perkembangan dimana penghuni dapat mengembangkan hunian nya sesuai kebutuhan nya sebagai jawaban permasalahan kota.
\end{abstract}

Kata Kunci-Permukiman kumuh, Masyarakat Kota, Hunian, Incremental.

\section{PENDAHULUAN}

$\mathrm{S}$ EPERTI yang sedang terjadi di negara berkembang, laju perekonomian semakin cepat. Pertumbuhan kota semakin cepat. Kota-kota besar semakin menunjukkan pertumbuhannya dan semakin maju. Namun, kemajuan kota juga diikuti dengan tumbuhnya permukiman kumuh di kota besar, seakan sebuah kota besar tidak bisa lepas dari permukiman kumuh.

Di Jakarta, permukiman kumuh muncul akibat dari urbanisasi. Urbanisasi adalah sebuah perpindahan penduduk yang dilakukan oleh penduduk di daerah rural ke daerah urban. Perpindahan ini dapat dipicu dari faktor ekonomi dan sosial. Namun, kecilnya angka pendidikan di Jakarta (Gambar 1) mengakibatkan sulitnya para penduduk untuk mencari pekerjaan, dan pada akhirnya mereka terpaksa untuk menganggur atau melakukan pekerjaan serabutan. Sedangkan, kebutuhan hidup di Jakarta relatif mahal. Masyarakat yang tidak mampu kemudian memilih tinggal pada lahan informal yang biasanya terletak di daerah sub-urban (Gambar 2). Dengan minimnya infrastruktur dan kemampuan masyarakat untuk memperbaiki lingkungannya, maka muncul lah permukiman kumuh pada kota [1].

\section{PENDEKATAN DESAIN}

Pendekatan desain yang dipilih adalah Incremental Housing dan Green Architecture. Incremental Housing adalah sebuah proses dimana hunian di bangun step by step dan dikembangkan seiring berjalannya waktu untuk meningkatkan kualitas dan luasan. Hunian yang awalnya sudah terbangun, memungkinkan untuk dikembangkan sesuai kebutuhan penghuni [2]. Dalam hal ini, hunian yang nantinya dapat berkembang dapat digunakan menjadi lahan usaha untuk mengembangkan perekonomian.

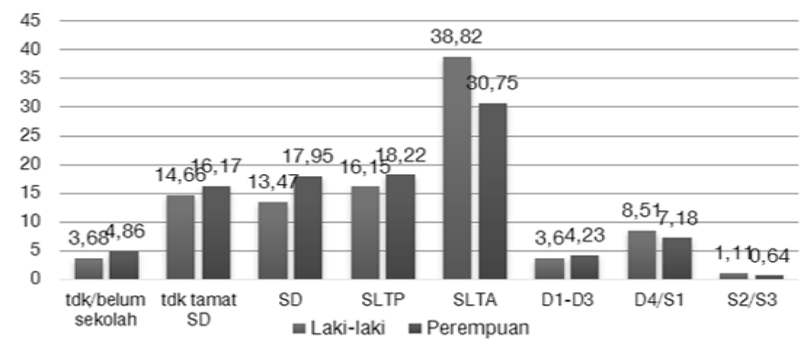

Gambar 1. Diagram Tingkat Pendidikan Jakarta (Sumber:BPS)

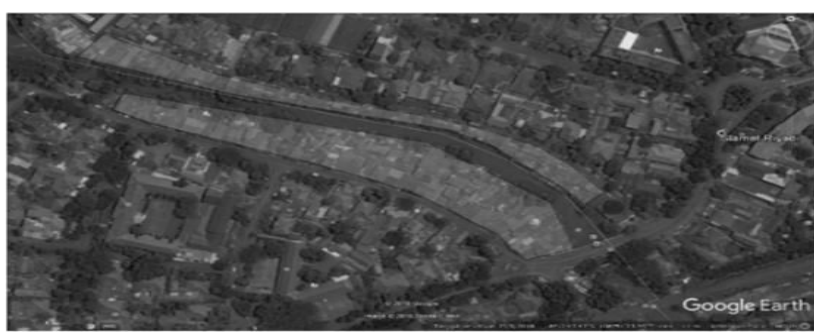

Gambar 2. Lokasi Permukiman kumuh (Sumber:Google Earth)

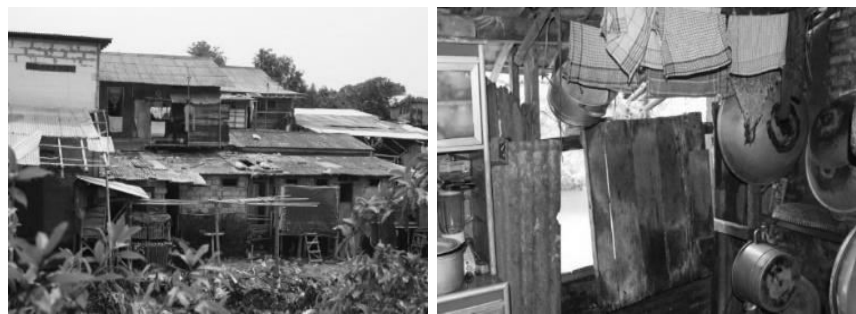

Gambar 3 . Permukiman Kumuh Jakarta (Sumber: dokumentasi pribadi).

Lalu Green Architecture digunakan sebagai parameter kualitas hunian yang akan dibangun. Prinsip Green Architecture yang digunakan adalah prinsip yang dikemukakan oleh Brendan and Robert Vale, yaitu : Conserving Energy, Minimizing New Resource, Working With Climate, Respect for User, Respect for Site, Holism [3]. Di dalam Incremental model, hunian tidak lagi dianggap sebagai sebuah unit statis, tetapi lebih sebagai pemecahan menjadi komponen-komponen yang lebih kecil. Tiga fase di dalam proses Incremental, yaitu:

1. Land Access

Ketersediaan lahan untuk pembangunan. Untuk lahan informal, akses lahan didapatkan dari keputusan atau kebijakan pemerintah. Namun bisa juga dari pengadaan lahan multifungsi. 


\section{Construction of the Basic Housing Nucleus}

Pengadaan fungsi utama dari hunian seperti standarstandar dari hunian yang layak

3. Incremental Improvements

Proses pengembangan hunian berdasarkan kebutuhan dari penghuninya, yang terbangun dari sumber daya yang telah disediakan

Dalam penerapannya, hunian dibangun setengah jadi terlebih dahulu dan setengahnya dibiarkan kosong agar penghuni dapat menambahkan ruangan untuk kebutuhannya di masa depan. Kebutuhannya dapat berupa kamar tambahan jika anggota keluarganya bertambah, ataupun lahan usaha untuk menambahkan tingkat perekonomian penghuni, juga untuk menambah daya tarik masyarakat luar lahan untuk datang.

Rumah yang sudah jadi memiliki susunan ruangan-ruangan utama yang tidak bisa disusun sendiri oleh penghuni karena memiliki utilitas utama seperti dapur, kamar mandi dan kamar utama (Gambar 4). Lalu ruangan yang kosong dapat dikembangkan sesuai dengan kebutuhannya. Namun dibatasi oleh struktur utama hunian agar penghuni tidak dapat mengembangkan huniannya lebih dari batasan (Gambar 5).

\section{EKSPLORASI DESAIN}

\section{A. Zoning}

Penyusunan massa dilakukan dengan cara menentukan offset dari lahan dengan jarak $5 \mathrm{~m}$, yang gunanya adalah menentukan GSB dan Jalur Inspeksi. Langkah selanjutnya adalah membuat grid dengan ukuran yang sama dengan modul hunian pada lahan. Gunanya adalah untuk memasukkan hunian sebanyak-banyaknya dan untuk memudahkan penyusunan zoning. (Gambar 7).

\section{B. Eksplorasi Formal}

Dari Communal Space dan Public Space yang terbentuk, dihubungkan dengan sirkulasi yang gunanya adalah menghubungkan ruang-ruang interaksi menjadi ruang interaksi yang terintegrasi, dan menghubungkan satu cluster dengan cluster yang lain. Zoning untuk hunian membentuk sebuah Cluster-cluster yang nantinya merupakan pembagi untuk hal utilitas dan ruang interaksi (Gambar 8).

Modul-modul hunian yang telah tersusun ditumpuk kemudian hingga satu zoning memiliki 2 unit hunian (Gambar 9). Tujuannya adalah untuk dapat memasukkan hunian yang lebih banyak sebagai bentuk kompensasi lahan yang dipakai sebagai ruang publik. Untuk menambahkan kesan tradisional dan kesan kampung pada hunian, maka hunian mengadaptasi ornamen dan bentuk dari rumah adat Jakarta, yaitu Rumah Kebaya.

\section{Eksplorasi Sirkulasi}

Permukiman kumuh identik dengan tidak adanya infrastruktur yang baik, terutama sirkulasi. Sirkulasi memiliki peranan penting pada suatu permukiman. Fungsi dari sirkulasi adalah sebagai akses penghuni, pengunjung, juga petugas jika terjadi bencana. Dengan absennya sirkulasi, petugas pemadam tidak dapat mengakses rumah yang mengalami kebakaran. Hal ini lah yang menyebabkan fatal nya kebakaran pada suatu permukiman kumuh (Gambar 10).

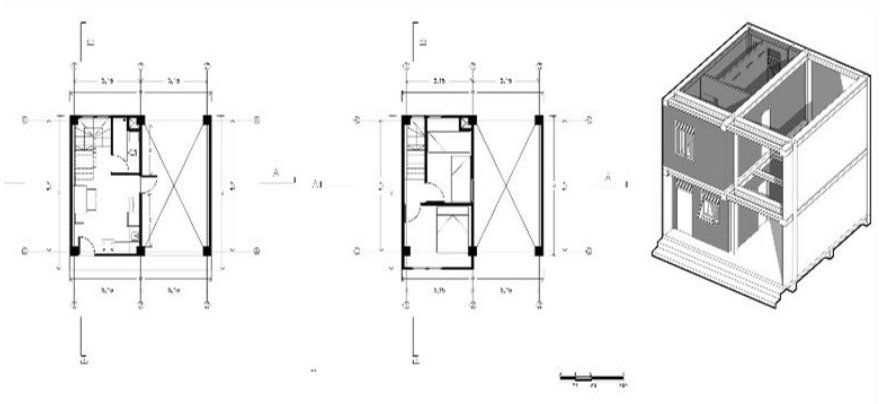

Gambar 4. Denah Rumah.

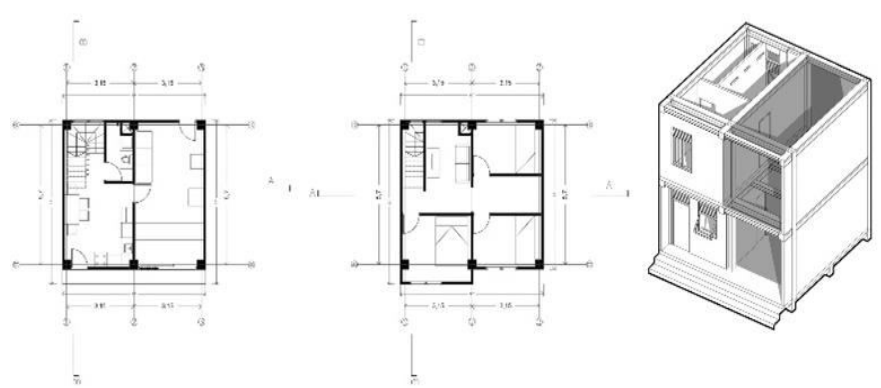

Gambar 5. Denah Rumah Berkembang.

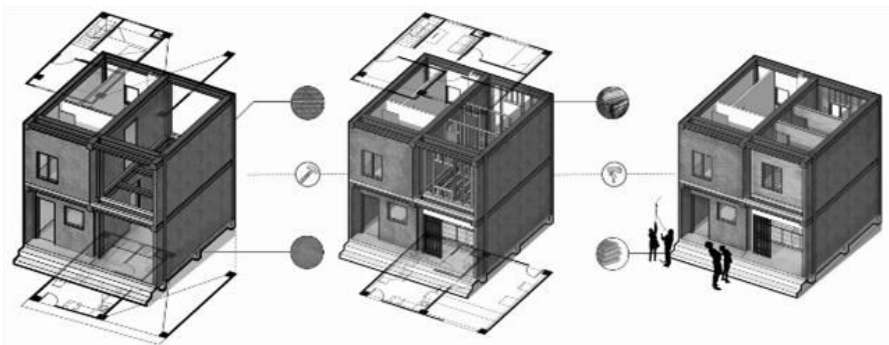

Gambar 6. Diagram Pengembangan Hunian.

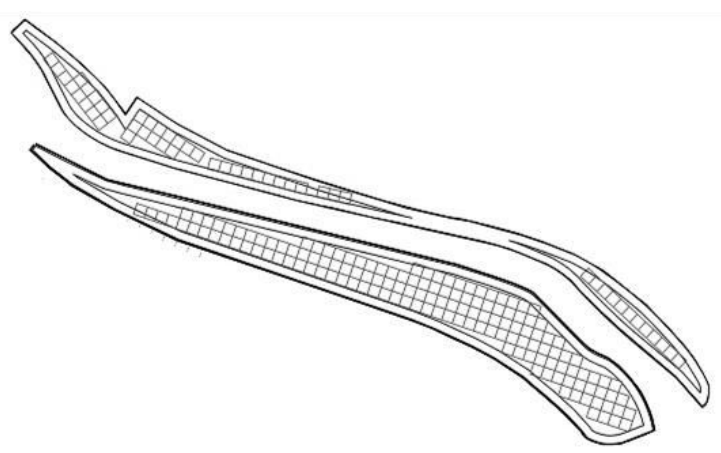

Gambar 7. Grid Peta Eksisting.

Solusi yang hadir adalah membuka sirkulasi dari Clustercluster yang terbentuk dengan menghubungkan antar Communal Space. Selain itu, dengan adanya jalur inspeksi pada bantaran kali, akses pejalan dapat ditarik mendekat sungai, agar masyarakat lebih memiliki sense terhadap sungai. Jalur inspeksi pun dapat dialih fungsikan menjadi Public Space, tempat dimana masyarakat setempat dan kota berinteraksi dan memiliki kegiatan bersama untuk menciptakan keharmonisan. 


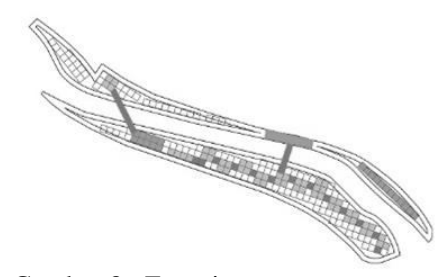

Gambar 8. Zonasi.
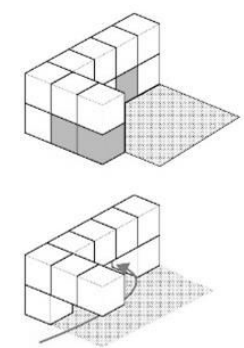

Gambar 9 . Modul Hunian.

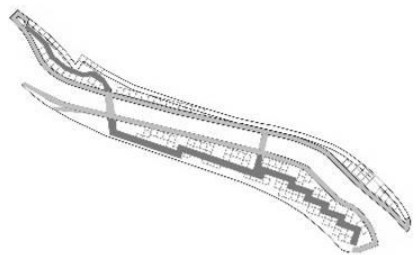

Gambar 10. Sirkulasi.

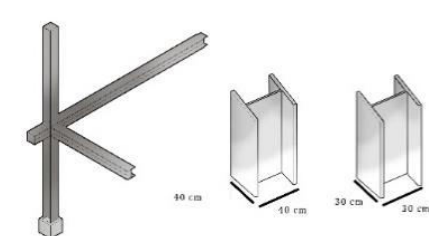

Gambar 11. Struktur Baja.

\section{Eksplorasi Teknis}

Dengan menggunakan struktur baja profil I, struktur baja disusun secara post and beam dengan ukuran kolom utama $30 \times 30 \mathrm{~cm}$ untuk hunian dan 40x40 $\mathrm{cm}$ untuk kolom penyangga tempat masuk (Gambar 11). Penggunaan struktur baja bertujuan agar pemasangan dan pembongkaran mudah dilakukan, dan memungkinkan untuk mendaur ulang kembali strukturnya.

Pada dasarnya, rumah dibagi menjadi dua bagian yang dibatasi oleh struktur, dua bagian rumah yaitu Rumah Jadi dan Rumah Berkembang. Rumah Jadi menggunakan material batu bata, karena terdapat utilitas dan dapur, yang rentan. Selain itu, rumah jadi menggunakan batu bata agar terkesan permanen.

\section{KESIMPULAN}

Permukiman kumuh adalah hasil dari perkembangan zaman dan sebuah kota besar. Keberadaannya tidak bisa dihindari, karena berbagai macam faktor, namun permukiman kumuh
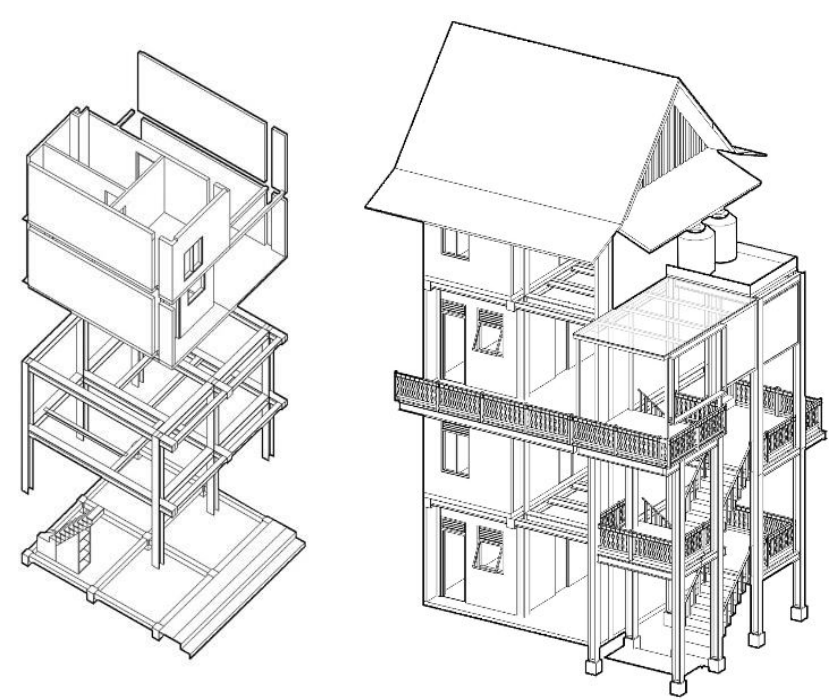

Gambar 12. Aksonometri Hunian.

merupakan indikasi dari perkembangan zaman. Kita sebagai arsitek dituntut untuk lebih kritis melihat masalah ini dan menawarkan penyelesaiannya.

Sebuah kawasan yang padat di redesain dan mengganti nya dengan susunan kawasan yang lebih tertata. Konsep yang diutamakan adalah pembukaan ruang publik dan komunitas. Ruang publik ini akan membuka sirkulasi orang dan angin untuk masuk ke area lahan. Setelah itu kualitas hunian diperbaiki dalam segi material dan penataan ruang nya. Dengan perbaikan mendasar yang terjadi pada lingkungan kumuh, diharapkan memicu pemeliharaan dari penghuni nya untuk menjaga kawasannya dan mengembangkannya.

\section{DAFTAR PUSTAKA}

[1] J. Silas, "Perumahan Dalam Jejak Paradox," Surabaya, 2015.

[2] J. F. C. Turner, Freedom to Build. New York: Macmillan Publishing Co, 1972.

[3] V. Brenda and V. Robert, Green Architecture: Design for Sustainable Future. London: Thames \& Hudson Ltd, 1991. 